\title{
Next-Generation Stem Cell Therapy: Genetically Modified Mesenchymal Stem Cells for Cardiac Repair
}

\author{
Editorial to: "Mesenchymal Stem Cells with eNOS Over-Expression Enhance Cardiac \\ Repair in Rats with Myocardial Infarction" by Leilei Chen et al.
}

\author{
Shathiyah Kulandavelu ${ }^{1}$. Wayne Balkan ${ }^{1,2}$ • Joshua M. Hare ${ }^{1,2}$
}

Published online: 22 February 2017

(C) Springer Science+Business Media New York 2017

\begin{abstract}
Although therapeutic advances have progressively reduced annual deaths from heart disease, cardiovascular disorders remain the leading cause of mortality and morbidity worldwide [1]. A main new therapeutic target is actual regeneration, fully repairing infarcted regions and restoring functioning myocardium following injury. In this regard, over the last $\sim 15$ years, the use of cell-based therapy has emerged as a leading approach to promoting myocardial regeneration and reducing myocardial infarct scar size.

A variety of stem cell populations including mesenchymal, cardiac and bone marrow-derived mononuclear cells have been identified and evaluated for their regenerative potential for the treatment of heart disease. One of the most favorable candidates for cellular therapy is the mesenchymal stem cell (MSC). There is substantial data from in vitro [2], preclinical [3-5] and clinical [6-9] studies supporting a multifactorial mechanism of action for the cardioreparative effects of MSCs. Main mechanisms include: reducing fibrosis and inflammation; stimulating angiogenesis; restoring contractile function and stimulating proliferation and activity of endogenous cardiomyocytes and cardiac stem cells. Although MSC therapy is promising, numerous challenges remain, including the source of donor cells, methods of cell delivery, and survival of transplanted cells in vivo. As such, enhancing the therapeutic effects of MSCs either by preconditioning with
\end{abstract}

Joshua M. Hare

jhare@med.miami.edu

1 Interdisciplinary Stem Cell Institute, University of Miami Miller School of Medicine, P.O Box 016960 (R125), Biomedical Research Building, 1501 N.W. 10th Ave. Room 908, Miami, FL 33136, USA

2 Department of Medicine, University of Miami Miller School of Medicine, Miami, FL 33136, USA growth factors, hypoxia and/or drugs or through genetic modification is under active investigation. MSCs pre-conditioned by exposure to pro-angiogenic or anti-apoptotic growth factors $[10,11]$ such as hypoxia inducible factor-1 (HIF-1), vascular endothelial growth factor (VEGF), insulin-like growth factor [12], heme-oxygenase-1 or protein kinase B (Akt) show enhanced left ventricular (LV) function in animal models of MI. Similarly, stem cells transfected with angiopoietin-1, CXC chemokine receptor 4, PIM-1 kinase or stromalderived factor-1 showed enhanced engraftment and myocardial function, thereby preventing cardiac remodeling, in animal models of MI [10, 11, 13].

In this issue of Cardiovascular Drugs and Therapy, Chen et al. examined the therapeutic potential of MSCs overexpressing endothelial nitric oxide (NO) synthase (eNOS/NOS3) for the treatment of ischemic cardiac injury in rats [14]. NO produced by eNOS plays a broad range of regulatory roles in the cardiovascular system [15-17] including promotion of vasodilation, modulation of myocardial contractile responses, nitrosoredox imbalance, angiogenesis and inflammation. eNOSderived NO plays a cardioprotective role following $\mathrm{MI}$ as shown by eNOS knockout (KO) mice [18] which exhibited left ventricular (LV) dysfunction and enhanced interstitial fibrosis whereas cardiomyocyte-specific eNOS overexpressing mice [19] showed enhanced LV function and decreased myocyte hypertrophy following MI. Furthermore, local transfer of eNOS into ischemic rat hearts increased NO bioavailability, stimulated neovascularization, attenuated cardiac remodeling and suppressed oxidative stress associated apoptosis [20,21]. Thus, eNOS may be an ideal candidate to enhance the cellular and therapeutic effects of MSCs.

Chen et al. [14] showed that adenoviral delivery of the human eNOS gene into mouse bone marrow-derived MSCs (BM-MSCs) ameliorated the ischemic injury in rats. The combination of eNOS gene delivery and MSCs reduced infarct 
size, improved hemodynamic parameters and increased capillary density [14]. These findings are a first step in using genetically modified MSCs that overexpress eNOS for the treatment of ischemic injury.

What are the mechanisms by which overexpressing eNOS can lead to improved therapeutic potential of MSCs in cardiac protection and tissue regeneration? Secretion of pro-angiogenic and pro-arteriogenic factors by MSCs is thought to be essential for the regenerative process following myocardial injury and NO plays an important regulatory role in angiogenesis and vasculogenesis. eNOS-derived NO, coupled with VEGF signaling, promotes endothelial cell-mediated angiogenesis [22, 23]. Both cGMP signaling and S-nitrosylation mediate the proangiogenic effects of NO. Furthermore, environments with nitroso-redox imbalance, such as found during ischemia and heart failure, induce regenerative processes. Hypoxia triggers angiogenesis via upregulation of $\mathrm{HIF} 1 \alpha$, which stimulates transcription of VEGF and heme-oxygenase (HO-1), a mechanism that is enhanced by eNOS-mediated protein S-nitrosylation [24, 25]. Male mice lacking S-nitrosoglutathione reductase $\left(\mathrm{GSNOR}^{-/}\right.$mice), a denitrosylase that regulates S-nitrosylation, exhibit constitutively S-nitrosylated HIF- $1 \alpha$ with increased binding to the VEGF gene [26]. These mice also manifest cardio-protection after MI that is associated with increased myocardial capillary density [26, 27]. Paradoxically, bone marrowderived MSCs from $\mathrm{GSNOR}^{-/}$mice exhibit reduced endothelial differentiation capacity ex vivo [28], illustrating the complicated and cell lineage-specific relationship between cardiac remodeling and nitroso-redox state. In addition, $\mathrm{GSNOR}^{-/-}$mice exhibit improved post-myocardial infarction regenerative activity, characterized by enhanced turnover of cardiomyocytes and cardiac stem cells (CSCs) [27]. Endogenous CSCs and other resident cardiac progenitor cells are thought to proliferate after MI to support cardiac repair. Furthermore, both MSCs and eNOS possess anti-inflammatory capacities, thus the combined treatment may work to modulate inflammation, thereby preventing extensive cell death and promoting the capacity for the cells to proliferate and renew.

Cell pre-conditioning and genetic modification are promising options in augmenting MSC- and other stem cell-based therapy. Chen et al. [14] showed that the combination of eNOS and MSCs may represent a promising cocktail with the potential to improve cardiac repair following ischemic injury. Direct, in vivo comparisons are needed to ascertain the most effective therapeutic approach for different types of heart disease. For example, the best cell pre-conditioning/genetic modification cocktail protocol for treatment of acute myocardial infarction may not be optimal therapeutic treatment for chronic myocardial infarction or heart failure with preserved ejection fraction. The next step will be to address efficiency and safety concerns by performing appropriate large animal studies, before this combined treatment can be taken into the clinical setting.

\section{References}

1. Mozaffarian D, Benjamin EJ, Go AS, Arnett DK, Blaha MJ, Cushman M, et al. Heart disease and stroke statistics-2015 update: a report from the American Heart Association. Circulation. 2015;131(4):e29-322.

2. Gnecchi M, He H, Liang OD, Melo LG, Morello F, Mu H, et al. Paracrine action accounts for marked protection of ischemic heart by Akt-modified mesenchymal stem cells. Nature Med. 2005;11(4):367-8.

3. Schuleri KH, Feigenbaum GS, Centola M, Weiss ES, Zimmet JM, Turney J, et al. Autologous mesenchymal stem cells produce reverse remodelling in chronic ischaemic cardiomyopathy. Eur Heart J. 2009;30(22):2722-32.

4. Hatzistergos KE, Quevedo H, Oskouei BN, Hu Q, Feigenbaum GS, Margitich IS, et al. Bone marrow mesenchymal stem cells stimulate cardiac stem cell proliferation and differentiation. Circ Res. 2010;107(7):913-22.

5. Amado LC, Schuleri KH, Saliaris AP, Boyle AJ, Helm R, Oskouei $\mathrm{B}$, et al. Multimodality noninvasive imaging demonstrates in vivo cardiac regeneration after mesenchymal stem cell therapy. J Am Coll Cardiol. 2006;48(10):2116-24.

6. Karantalis V, DiFede DL, Gerstenblith G, Pham S, Symes J, Zambrano JP, et al. Autologous mesenchymal stem cells produce concordant improvements in regional function, tissue perfusion, and fibrotic burden when administered to patients undergoing coronary artery bypass grafting: the prospective randomized study of mesenchymal stem cell therapy in patients undergoing cardiac surgery (PROMETHEUS) trial. Circ Res. 2014;114(8):1302-10.

7. Heldman AW, DiFede DL, Fishman JE, Zambrano JP, Trachtenberg $\mathrm{BH}$, Karantalis V, et al. Transendocardial mesenchymal stem cells and mononuclear bone marrow cells for ischemic cardiomyopathy: the TAC-HFT randomized trial. JAMA. 2014;311(1):62-73.

8. Hare JM, Traverse JH, Henry TD, Dib N, Strumpf RK, Schulman SP, et al. A randomized, double-blind, placebo-controlled, doseescalation study of intravenous adult human mesenchymal stem cells (prochymal) after acute myocardial infarction. J Am Coll Cardiol. 2009;54(24):2277-86.

9. Hare JM, DiFede DL, Castellanos AM, Florea V, Landin AM, ElKhorazaty $\mathrm{J}$ et al. Randomized Comparison of Allogeneic Vs. Autologous Mesenchymal Stem Cells for Non-lschemic Dilated Cardiomyopathy: POSEIDON-DCM Trial. J Am Coll Cardiol. 2017;69(5):526-37.

10. Karantalis V, Hare JM. Use of mesenchymal stem cells for therapy of cardiac disease. Circ Res. 2015;116(8):1413-30.

11. Golpanian S, Wolf A, Hatzistergos KE, Hare JM. Rebuilding the damaged heart: mesenchymal stem cells, cell-based therapy, and engineered heart tissue. Physiol Rev. 2016;96(3):1127-68.

12. Guo J, Lin G, Bao C, Hu Z, Chu H, Hu M. Insulin-like growth factor 1 improves the efficacy of mesenchymal stem cells transplantation in a rat model of myocardial infarction. J Biomed Sci. 2008;15(1):89-97.

13. Kulandavelu S, Karantalis V, Fritsch J, Hatzistergos KE, Loescher VY, McCall F, et al. Pim1 kinase overexpression enhances ckit + Cardiac stem cell cardiac repair following myocardial infarction in swine. J Am Coll Cardiol. 2016;68(22):2454-64.

14. Chen L, Zhang Y, Tao L, Yang Z, Wang L. Mesenchymal stem cells with eNOS over-expression enhance cardiac repair in rats with myocardial infarction. Cardiovasc Drugs Ther. 2017;31, this issue.

15. Varghese P, Harrison RW, Lofthouse RA, Georgakopoulos D, Berkowitz DE, Hare JM. Beta(3)-adrenoceptor deficiency blocks nitric oxide-dependent inhibition of myocardial contractility. J Clin Invest. 2000;106(5):697-703.

16. Hare JM. Nitroso-redox balance in the cardiovascular system. New Engl J Med. 2004;351(20):2112-4. 
17. Keaney Jr JF, Hare JM, Balligand JL, Loscalzo J, Smith TW, Colucci WS. Inhibition of nitric oxide synthase augments myocardial contractile responses to beta-adrenergic stimulation. Am J Phys. 1996;271(6 Pt 2):H2646-52.

18. Landmesser U, Engberding N, Bahlmann FH, Schaefer A, Wiencke A, Heineke A, et al. Statin-induced improvement of endothelial progenitor cell mobilization, myocardial neovascularization, left ventricular function, and survival after experimental myocardial infarction requires endothelial nitric oxide synthase. Circulation. 2004;110(14):1933-9.

19. Janssens S, Pokreisz P, Schoonjans L, Pellens M, Vermeersch P, Tjwa M, et al. Cardiomyocyte-specific overexpression of nitric oxide synthase 3 improves left ventricular performance and reduces compensatory hypertrophy after myocardial infarction. Circ Res. 2004;94(9):1256-62.

20. Chen LL, Zhu TB, Yin H, Huang J, Wang LS, Cao KJ, et al. Inhibition of MAPK signaling by eNOS gene transfer improves ventricular remodeling after myocardial infarction through reduction of inflammation. Mol Biol Rep. 2010;37(7):3067-72.

21. Chen LL, Yin H, Huang J. Inhibition of TGF-betal signaling by eNOS gene transfer improves ventricular remodeling after myocardial infarction through angiogenesis and reduction of apoptosis. Cardiovasc Pathol. 2007;16(4):221-30.

22. Papapetropoulos A, Garcia-Cardena G, Madri JA, Sessa WC. Nitric oxide production contributes to the angiogenic properties of vascular endothelial growth factor in human endothelial cells. J Clin Invest. 1997;100(12):3131-9.

23. Ahmad S, Hewett PW, Wang P, Al-Ani B, Cudmore M, Fujisawa T, et al. Direct evidence for endothelial vascular endothelial growth factor receptor-1 function in nitric oxide-mediated angiogenesis. Circ Res. 2006;99(7):715-22.

24. Pugh CW, Ratcliffe PJ. Regulation of angiogenesis by hypoxia: role of the HIF system. Nature Med. 2003;9(6):677-84.

25. Kim JH, Lee KS, Lee DK, Kim J, Kwak SN, Ha KS, et al. Hypoxiaresponsive microRNA-101 promotes angiogenesis via heme oxygenase-1/vascular endothelial growth factor axis by targeting cullin 3. Antioxid Redox Signal. 2014;21(18):2469-82.

26. Lima B, Lam GK, Xie L, Diesen DL, Villamizar N, Nienaber J, et al. Endogenous S-nitrosothiols protect against myocardial injury. Proc Nat Ac Sci USA. 2009;106(15):6297-302.

27. Hatzistergos KE, Paulino EC, Dulce RA, Takeuchi LM, Bellio MA, Kulandavelu S, et al. S-Nitrosoglutathione Reductase Deficiency Enhances the Proliferative Expansion of Adult Heart Progenitors and Myocytes Post Myocardial Infarction. J Am Heart Ass. 2015;4(7)

28. Gomes SA, Rangel EB, Premer C, Dulce RA, Cao Y, Florea V, et al. S-nitrosoglutathione reductase (GSNOR) enhances vasculogenesis by mesenchymal stem cells. Proc Nat Ac Sci USA. 2013;110(8): 2834-9. 